Essays I

\title{
Between Heaven and a Hard Place: Inhabiting the Space Between an Enchanted Past and a Utopian Future
}

$$
\text { by John Fahy }
$$

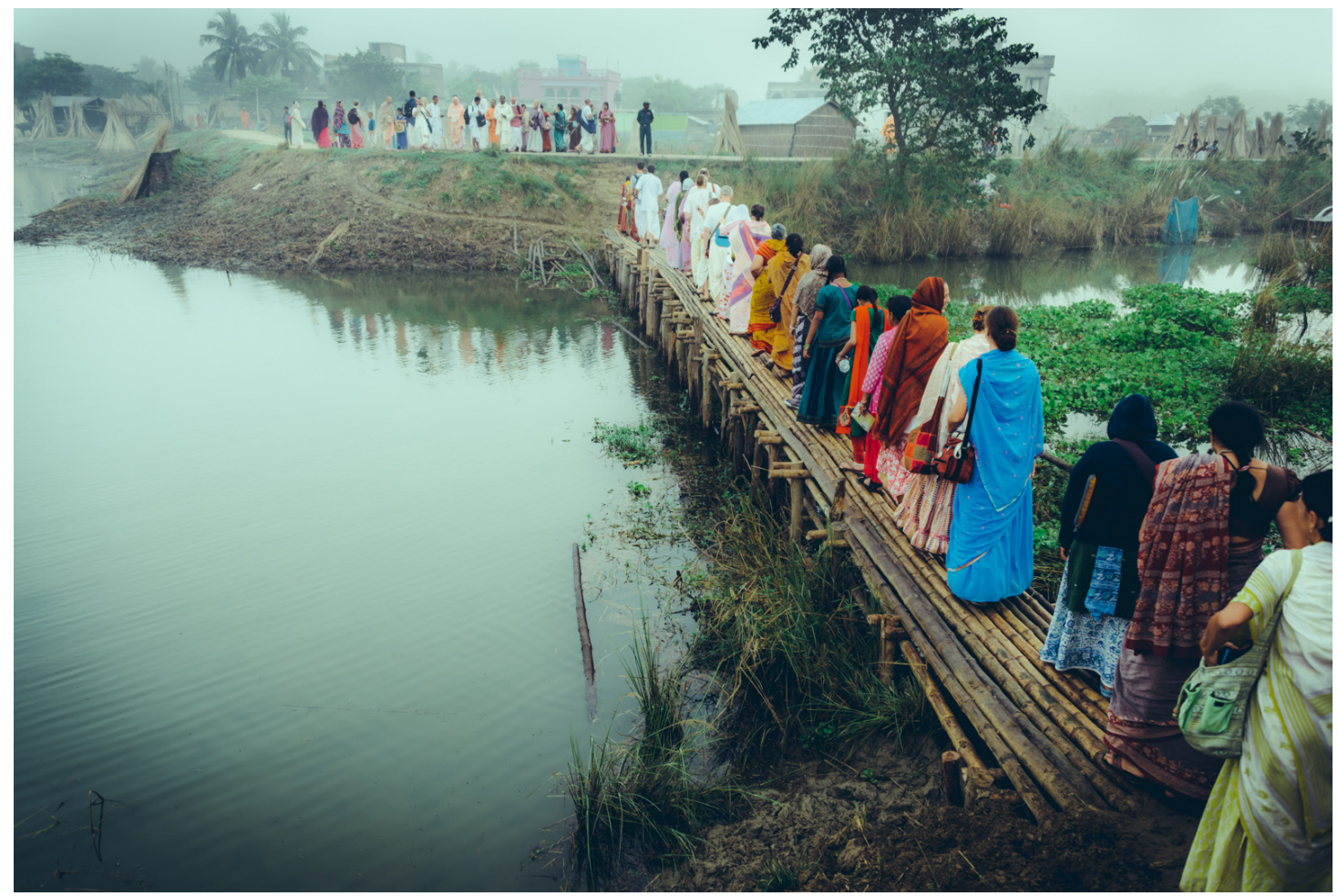

I. Parikrama (pilgrimage) around Mayapur 


\title{
Between Heaven and a Hard Place: Inhabiting the Space Between an Enchanted Past and a Utopian Future
}

\author{
by John Fahy
}

\begin{abstract}
This essay looks at how devotees of Krishna in Mayapur, West Bengal experience the space between an ideal past and a prophesied future. Through an affective and imaginative engagement with Vaishnav cultural history, devotees learn to relocate themselves in a particular temporal flow, within which both the past and future become constitutive horizons of the ethical imagination. I will focus on how the tradition of katha (storytelling) facilitates a convergence of temporalities, within which devotees are encouraged to routinely participate in the past. Such engagement with an enchanted past, I will argue, in turn informs devotees' imaginings of and aspirations for the ongoing development of an 'Ideal Vedic City'.
\end{abstract}

"The past is a foreign country: they do things differently there." The opening line of L.P. Hartley's novel The Go-Between (1958) evokes the familiar conception that at the heart of the notion of temporality is a sense of alterity; that the past, present and future are divergent spaces that require different modes of attention. In this essay, I will look at the ways in which both the past and the future impose themselves on, and are made meaningful in, the present, producing a sense of convergence. I will discuss the role that practising the past and imagining the future play in the everyday lives of the ISKCON community in Mayapur, West Bengal. ${ }^{1}$ In particular I will look at how storytelling, among other methods of invocation, facilitates an intense engagement with the past, which in turn informs aspirations and ideas for the future. In the context of Mayapur's utopian project of an 'Ideal Vedic City', visions of the future are anchored firmly in perceptions and performances of the past, which in Mayapur is not a 'foreign country', but the very ground on which devotees tread every day.

This essay addresses how, to quote Nancy Munn, the "ways of attending to the past also create modes of apprehending certain futures or of reconstructing a particular sense of past in the present that informs the treatment of 'the future in the present'" (1992:115). How do we evoke and engage with the past, and to what end? What is the nature of the relationship between the past, present and future and how do we construct meaningful temporalities that frame both ethical reflection and social action? In his popular work How Societies Remember (1989) Paul Connerton writes that, "our experience of the present very much depends on our knowledge of the past... and we will experience our present differently in accordance with the different pasts to which we are able to connect that past" (1989: 2). I am concerned here not only with how knowledge, but also practices of a particular past, inform devotees' imaginings of a prophesied future.

\section{Mayapur}

Though popularly regarded as a product of the counterculture that gripped America in the mid 1960's, the arrival of Vaishnavism in the West is but one chapter in a long history of revitalisation and reinvention that can be traced back to $15^{\text {th }}$ century Bengal (Sardella: 2013). It was in what is now modern-day Mayapur that Caitanya Mahaprabhu, considered to be an avatar of Krishna, was born in $1486 \mathrm{AD}$ and it was from here that he began his mission of promulgating the chanting of the holy name and instituted sankirtan (communal singing of the names of Krishna). Though he spent much of his later life in Puri, 'the Holy Dham', as Mayapur is commonly referred to, is a sacred space and a 'storied landscape' (Sarbadhikary: 2013) in the imagination and practise of devotees worldwide.

Surrounded by vast expanses of agricultural land and situated on the banks of the Ganges $130 \mathrm{~km}$ north of Kolkata, Mayapur was a typical rural Indian setting until the early 1970's. With little infrastructure and amidst a handful of small temples, a largely dispersed local population of subsistence farmers worked the land as generations had done before them. This all changed in 1972, with the arrival of the first ISKCON devotees in the area. In the 40 years since, Mayapur has been developing as the

1. International Society for Krishna Consciousness, popularly known as the 'Hare Krishnas'. 
headquarters of a global religious movement and is home to a community of approximately 4,000 devotees, both international and local. Srila Prabhupada (or Prabhupad), the founder of ISKCON, was determined that Mayapur would become a one-of-a-kind 'Ideal Vedic City' of 50,000 people, from which ISKCON's philosophy would spread around the world. As Mayapur continues to undergo dramatic social, infrastructural and economic transformation, as is symbolised in the construction of the Temple of Vedic Planetarium (TOVP), the founder's vision of an 'ideal city' serves as the narrative within which devotees frame their ideas of a utopian future.

\section{Practising the Past}

8 a.m. approaches and international devotees begin moving from the temple downstairs to a large room on the first floor, where the daily Srimad Bhagavatam class is being set up. ${ }^{2}$ I find a space to sit while some young devotees enthusiastically scramble to make sure everything is in order. The particular sloka (verse) must be written on a blackboard, the asana (guru's seat) need to be prepared, and a flower garland is set aside for offering to the speaker. Some cushions are laid out for senior members of the community, while others simply sit on straw mats that cover the cold marble, with women on the right and men on the left. Some devotees chat while most use these few minutes to chant the maha-mantra ("Hare Krishna, Hare Krishna, Krishna Krishna, Hare Hare, Hare Rama, Hare Rama, Rama Rama, Hare Hare"). All around me sporadic syllables of 'Hare', 'Krishna' and 'Rama' penetrates the thickening murmur of communal chanting, while the room fills up. Under the piercing gaze of a Prabhupad picture hanging on the wall, and as the ecstatic kirtan (communal singing of devotional songs) downstairs echoes its last crescendo, the speaker signals the beginning of the class, singing 'Jaya Radha Madhava' to the chime of kartals.

This is a typical scene every morning in the ISKCON temple in Mayapur. The classes follow a basic formula that includes reading slokas from the Srimad Bhagavatam, translating individual words from the Sanskrit text, and a short kirtan. This is followed by a sermon of sorts, picking up on important themes in the text. The speaker is usually a senior devotee, sometimes a guru, though on occasion women and less senior members of the community are also given a chance to give class. Depending on the speaker and the topic at hand, the tone ranges from pedagogic to nostalgic, and at times, can be deeply personal. Some classes are necessarily technical, dealing with content such as Vedic cosmology, while others, discussing virtues such as mercy or humility, might be based on personal experience or interactions with Prabhupad in the 1970's. There is some time left at the end for questions, but typically this is not so much an open forum as it is a space for clarifying specific points from the text.

The daily classes were central to Prabhupad's mission of spiritual education, and remain a staple in ISKCON temples all over the world. They are not only pragmatic in that there is an obvious need for educating aspiring devotees in what is for some a foreign philosophy, but they also facilitate what is colloquially rendered as 'hearing the Bhagavatam'. Like most of ISKCON's practices, this has its roots in wider Vaishnava tradition. Gathering with other devotees to 'hear the Bhagavatam' is an ethical imperative and is at the heart of a set of practices by which devotees identify as Vaishnavas. Other such practices include chanting on beads, attending the temple, preaching, performing seva (service) and following the regulative principles. While 'hearing the Bhagavatam' specifically refers to recitations or discussions based around the text itself, these classes also make space for a closely related and equally important tradition, katha (storytelling).

While the past is routinely re-enacted through ritual, parikramas (pilgrimages), festivals, dramas, and 'hearing the Bhagavatam', central to devotees' practises of the past is katha. Along with Krishna's youth as a cowherd in Vrindavan, Caitanya's deeds in Nabadwip and Puri, and the lives and deeds of previous acharyas (spiritual leaders), stories such as these (referred to by devotees as 'pastimes') comprise a tapestry of tales that animate the storied landscape of Mayapur and locate devotees in a set of

2. The Srimad Bhagavatam, affectionately referred to as the 'ripened fruit of the Vedas' is the most important scriptural source for ISKCON devotees. While this English class takes place upstairs there is a Bengali class downstairs in the temple for local devotees. 
convergent temporalities, sewn together in both historical and mythical time. ${ }^{3}$ ISKCON's preference for some pastimes over others can be linked not only to the sacred geography of India, but also to historical, philosophical and moral concerns, as have been inherited from the late $19^{\text {th }}$ century Vaishnav revival to which ISKCON traces its lineage. Popular pastimes include the child Krishna displaying the whole universe in his mouth to his mother Yasoda, the adolescent Krishna playing tricks on the gopis (cowherd girls), and the mature Krishna revealing his divinity to Arjuna on the battlefield. Though the tradition of katha can encompass stories from different places in different times (both sacred and profane), in Mayapur, the most popular pastimes are those of Caitanya's life and times, his ecstatic devotion, his encounters with renowned philosophers, and early stories of sankirtan in the streets of Nabadwip. While these pastimes are referred to in the flow of everyday conversation, it is in the pedagogic setting of the daily classes that they are elaborately recounted, and explicitly interpreted by a senior devotee for the congregation. As one of many examples of such pastimes, I refer here to the popular story of Jagai and Madhai.

This story is said to have taken place in early $16^{\text {th }}$ century Nabadwip, the area within which Mayapur is located, and is probably most faithfully rendered, for ISKCON devotees, in Prabhupad's own words: ${ }^{4}$

Jagai and Madhai were two brothers born in Navadvipa (Nabadwip) in a respectable brahmana family who later became addicted to all kinds of sinful activities. By the order of Lord Caitanya, both Nityananda Prabhu and Haridasa Thakura used to preach the cult of Krishna consciousness door to door. In the course of such preaching they found Jagai and Madhai, two maddened drunken brothers, who, upon seeing them, began to chase them. On the next day, Madhai struck Nityananda Prabhu on the head with a piece of earthen pot, thus drawing blood. When Sri Caitanya Mahaprabhu heard of this, He immediately came to the spot, ready to punish both brothers, but when the all-merciful Lord Gauranga (Caitanya Mahaprabhu) saw Jagai's repentant behaviour, He immediately embraced him. By seeing the Supreme Personality of Godhead face-to-face and embracing Him, both the sinful brothers were at once cleansed. Thus they received initiation into the chanting of the Hare Krishna maha-mantra from the Lord and were delivered.

In my first couple of months in Mayapur I had already heard the pastime of Jagai and Madhai several times, each time more or less elaborately rendered. There were occasions, for example, when a devotee would simply mention "just like Jagai and Madhai" and I was expected to understand the didactic reference in the context of our discussion. This is a popular pastime that serves to exemplify a range of Vaishnav virtues, from the all-encompassing ideal of mercy (think of Jagai and Madhai as the Mary Magdalenes of Vaishnavism) to the radical self-transformation that underpins ISKCON's philosophy and practises. Pastimes like that of Jagai and Madhai are sources not only of morals, ideals and aesthetics, but also of historical facts. They shed light not only on the lofty virtues of an ideal Vaishnav but are also valued as sources of historical knowledge in and of themselves, as they contain tangential but cherished details of what is described as Vaishnav culture. When devotees discuss, for example, the role of women in the community, conflict resolution, preaching strategies, or what an ideal city should look like, it is to stories such as this that they will turn to legitimate their perspective, along with quotes from Prabhupad and scriptures such as the Srimad Bhagavatam.

While the tradition of katha is of course pedagogic, it would be misleading (and I was indeed misled) to think that the ultimate goal was simply the transmission, acquisition or exchange of knowledge. As Lawrence Babb writes in relation to another Hindu sect, the Brahma Kumari in Delhi, “...the emphasis is not just on knowledge, but on knowing-as-an-experience" (1982: 59). Inherited from traditional Indian epistemology, knowledge in the purest sense is not simply an object of acquisition but more importantly an object of experience. Devotees' experience of their present very much depends, not just on their knowledge, but on their performances of the past, as are routinised through practises

3. The term 'pastime' here is an English rendering of the Sanskrit lila, and is used most commonly to refer to the life and deeds of Krishna and the exalted Vaishnavas.

4. Extract from Sri Caitanya-caritamrita, Adi-lila, Chapter 17, Text 17 (Prabhupada: 1975). 
John Fahy
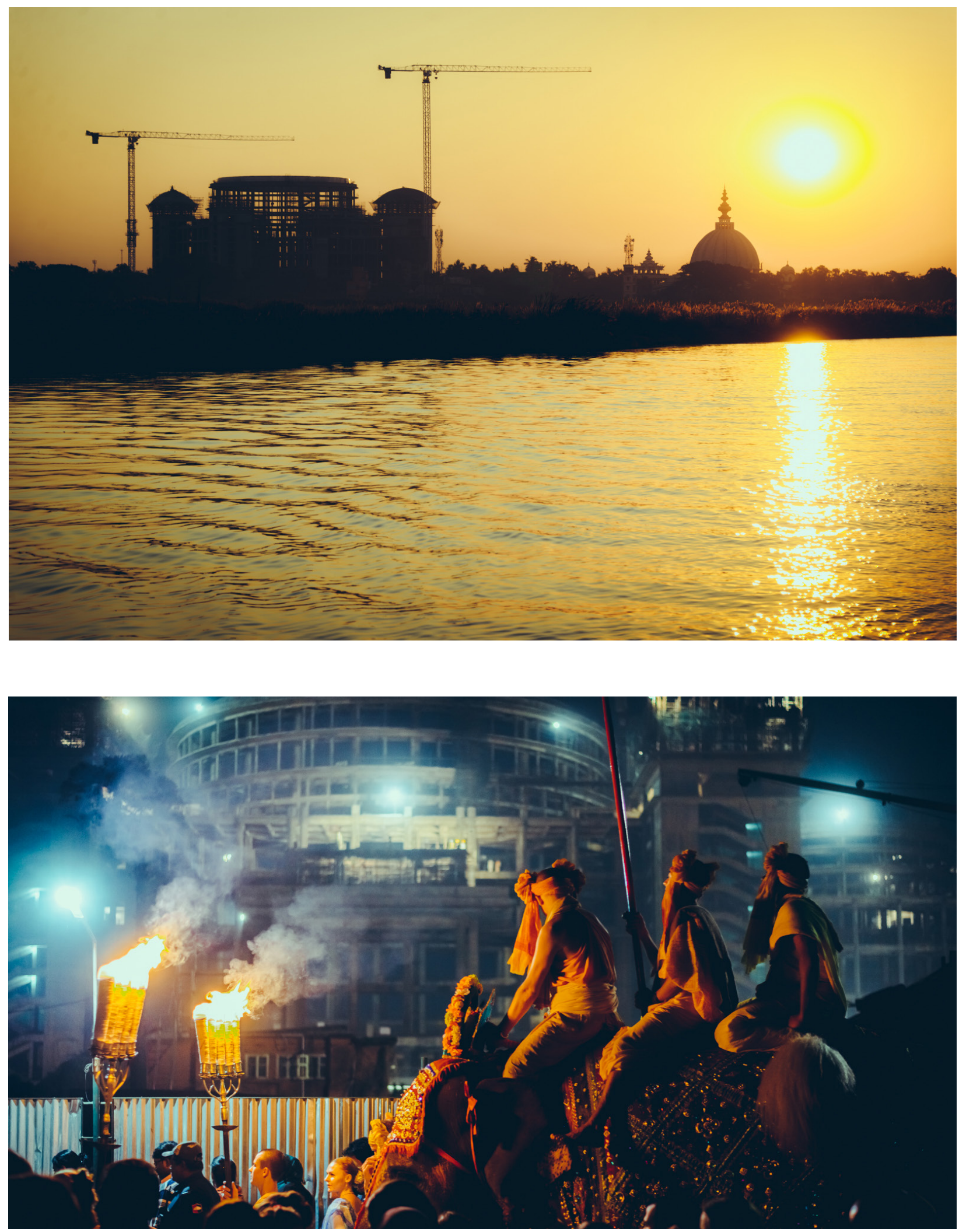

(TOP) 2.The Temple of Vedic Planetarium viewed from the Ganges

(BOTTOM) 3.The Past and the Future 


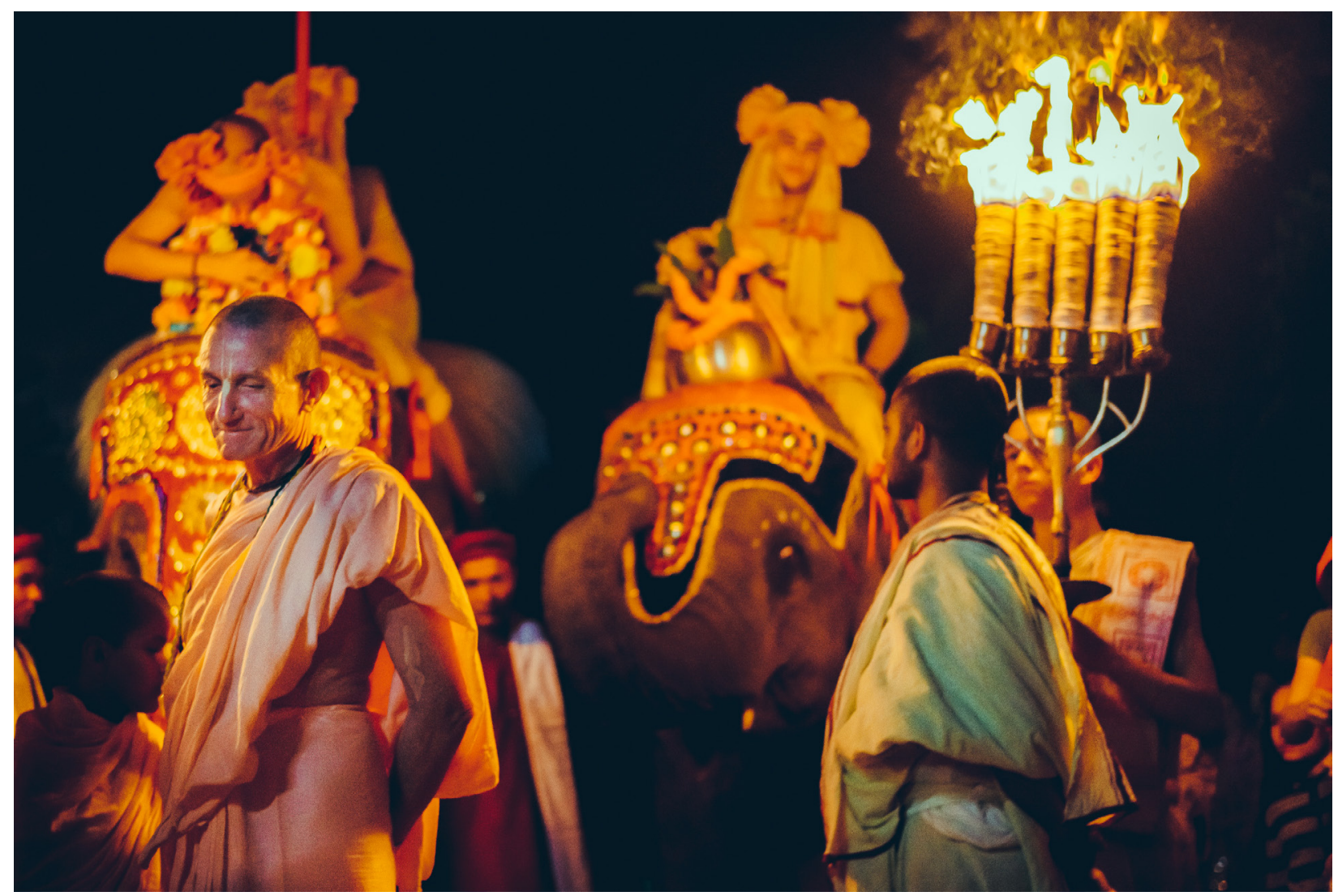

4. Hati Procession

like 'hearing the Bhagavatam' and katha in the setting of the daily classes. Devotees' understanding and experience of Vaishnava culture is nurtured in the context of an affective and imaginative participation in pastimes such as that of Jagai and Madhai.

A reorientation of the self towards Krishna necessitates a relocation of the self in a particular temporal flow; not of distancing, but of convergence, as is made intelligible in the space provided by katha. Just as one ought to reside in a sacred space (tirtha), one ought to learn to inhabit a sacred time, and it is within the ethically charged space facilitated by practises of katha and 'hearing the Bhagavatam', I suggest, that this is made meaningful in the lives of devotees in Mayapur. Pastimes such as the story of Jagai and Madhai are a basic currency of imaginative and ethical exchange, and are mobilised in a wide range of scenarios, dealing with interpretations of the past, conflicts of the present, and imaginings of the future.

\section{Imagining the Future}

While it is to an enchanted history that devotees look for their morals, ideals and role models, it is into a prophesied future that they project their hopes, desires and satisfactions (Moore: 2011). This future is itself a projection not just of knowledge, but of practices of the past, such as katha, which are mediated through everyday experiences of an emergent present. As Mayapur continues to develop, it is around the utopian vision of an 'Ideal Vedic City' that devotees' imaginings of the future cohere, framing discourses of both self-cultivation and social transformation.

As the temple of the Vedic Planetarium (TOVP) takes shape, many devotees are asking what is an 'Ideal Vedic City'? Though Prabhupad often referred to plans for the development on his visits to Mayapur, he left his devotees to oversee the details of his grand ambitions. From the gaps between his recorded statements on the issue has sprung much debate, and there are divergent interpretations of what an Ideal Vedic City might look like. Firstly (though a full treatment is outside the scope of this essay) is the question of what Prabhupad meant by Vedic. This term can be used to refer to a body of literature or a period in history, for example, but for ISKCON devotees, 'Vedic' connotes a living and 
breathing culture. Thinking about the development of Mayapur, one guru suggested an alternative: "It's a Gaudiya Vaishnav City, it's not entirely Vedic...that Caitanya Vaishnavism which has that special bhakti flavour focused on Radha Krishna, Vrindavan and all that, right..." Another senior devotee, in response to my question "What is Vedic?", simply laughed:"You tell me!"

This idea of an Ideal Vedic City was first conceived by the Vaishnava spiritual leader (and father of Prabhupad's guru), Bhaktivinodh Thakur, in the late $19^{\text {th }}$ century. He had a vision of an adbhutamandira (commonly translated as 'extraordinary temple'), around which a spiritual city would grow. From this new centre for preaching and education, the chanting of the holy name would spread to 'every town and village' in the world. In the hands of

Prabhupad, Bhaktivinodh's vision became a prophecy. Up until recent years, however, this Ideal City was just that: an ideal. The project of developing Mayapur necessarily took a back seat as, globally, ISKCON's fortunes and finances took a turn after the death of Prabhupad in 1977, and locally their ambitions were frustrated by an unsympathetic communist government. The 1980's in particular was a decade of decline, from which it took ISKCON a long time to emerge. At this point, although struggling in some parts of the world, the global movement of ISKCON, and in particular its Indian mission, have emerged resilient and rejuvenated. This is due mainly to ISKCON's ability to adapt to the changing dynamic of its following, evolving from, to borrow Roy Wallis' (1984) terminology, a "world-rejecting" to a "world-accommodating" movement, or from 'cult to congregation'. While under Prabhupad's guidance the majority of followers were brahmacharis (male celibate monks), householders (also referred to as congregational members) now represent over $90 \%$ of the worldwide demographic, according to ISKCON's own estimates. This rejuvenation is nowhere more evident than in Mayapur itself, as symbolised by the beginning of construction on the TOVP in 2010 and the ongoing building of residential high-rises around the ISKCON complex. The TOVP, when completed (in 2022) will be 35 storeys high and will be the tallest Hindu temple in the world (think St Paul's Cathedral in the middle of rural Indian rice fields). ${ }^{5}$ Plans for the temple include a chandelier representing Vedic cosmology, various exhibits outlining ISKCON's philosophy, and extensive landscaping and beautification of the surrounding area, but most importantly this will be the centerpiece of the Vedic City. As the superstructure pierces the skyline, this idea of an Ideal Vedic City is slowly becoming a tangible reality for devotees, both locally and globally.

The ambiguity that pervades Prabhupad's vision has not, however, hindered the development of Mayapur. Under the banner of 'Vedic culture' (sometimes made synonymous with 'Vaishnav'), devotees, through online forums, daily classes, and in casual conversations, continue to discuss and debate what they feel are the most important elements of a 'Vedic city' to emulate. One devotee argued online (on the community forum), for example, that, "Even if the Mayapur city has the best karmi (nondevotee) standards in the world but does not implement VEDIC ARCHITECTURE then no one has the right to call it a VEDIC city" (his emphasis). Referring to the socio-political system advocated by Krishna in the Bhagavad Gita, varnashrama dharma, another devotee asked, "If this is a Vedic city, where is the King? Where are the intelligent renounced Brahmans?" Yet another devotee insisted that, "We should really be promoting...extended family housing as was previously mentioned and the virtues that extended families bring to society". There are a wide variety of such perspectives, and interpretations tend to be based on expertise and personal preference, rather than organised groups advocating a particular agenda. The sources to which devotees turn to qualify their understandings are few, ranging from descriptions of urban centres in the Mahabharata and Srimad Bhagavatam, to Prabhupad's quotes on the topic, the pastimes recounted during classes, and on occasion, academic sources (though these are deeply mistrusted). Ideas and interpretations of what this city might look like orbit a wide array of perspectives, encompassing distinctly modern concerns such as waste management, recycling programs, and sustainable energy, alongside aesthetics, ideals and virtues of an enchanted past, as are transmitted

5. The TOVP is based on the design of St. Paul's Cathedral, Capitol Hill, the Taj Mahal and the Hagia Sophia (none of which, interestingly, are Hindu, let alone 'Vedic'). 
through the tradition of katha.

What has arisen in the cracks between Prabhupad's clear statements for the future city are fertile spaces where devotees invest their own priorities, interpretations and subjectivities into the broader narrative of an 'Ideal Vedic City'. Within these spaces devotees mobilise popular pastimes as a tool

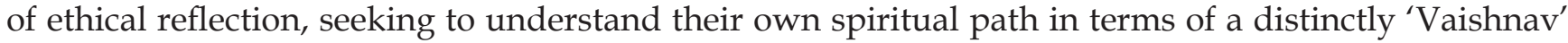
set of cultural practices. While devotees disagree on the details of what constitutes an ideal city, it is consistently the aesthetics of the past that are invoked to articulate the multitude of visions of the future that abound.

\section{Conclusion}

As objects of both knowledge and experience, the past and future become horizons of what Henrietta Moore (2011) calls the ethical imagination, around which explicit narratives of self-cultivation and social development cohere in a convergence of temporalities. Devotees come to the Srimad Bhagavatam and other classes in search of what they call 'realisations', which are typically described as moments of clarity where ISKCON's philosophy and the lives and teachings of the acharyas resonate profoundly with their personal experience and spiritual practices. Such realisations punctuate the process of selfcultivation, as devotees endeavor to put Krishna at the centre of their lives.

Devotees then do not come to passively 'hear' but rather to participate in and mobilise the stories of the past in a meaningful way in their own unfolding present. Katha is a window through which the past converges on the present, facilitating an engagement between the devotee and the sacred space of Mayapur. In attending these classes, devotees not only get acquainted with what at first is an unfamiliar cultural history, but learn to imbibe Vaishnava culture, morality and aesthetics, through an embodied and affective participation in the pastimes themselves. The morning class then is not so much a stage upon which knowledge of the past is transmitted, but a theatre within which the past itself is experienced. Hearing about Jagai and Madhai, for example, might lead a devotee to identify a need in their own spiritual practice for a focus on humility, or mercy, both of which are not only prominent virtues of an ideal Vaishnava but indispensable foundations of an 'ideal city'. Within the overarching narrative of an 'Ideal Vedic City', pastimes such as that of Jagai and Madhai are mobilised in an affective economy of ethical and interpretive exchange that is geared towards reconstructing the past in the space provided by an imagined future.

To live in Mayapur is to live with the past, to engage in a process of becoming, a process made intelligible by intense practices of subjectification whereby the devotee's energies are constantly invested in introspection. Through the tradition of katha, such introspection is facilitated by the collapsing of temporalities, where the past is experienced and the future imagined. As Nancy Munn (1992: 105) has pointed out, while anthropology has had much to say about different culture's "reckoning of time", we would do well to pay more attention to how they "reckon with time". This essay has attempted to describe how various practices and perceptions of the past determine devotees' everyday experiences of an emergent present and at the same time inform their orientation towards an imagined future. Through katha, devotees are encouraged to participate in a storied landscape, not only in the imagination, but in everyday practice, making comprehensible an experience and not just an ideal of 'Vedic culture'. It is from such experiences that devotees negotiate an understanding of their place on a temporal trajectory between an enchanted history and an unfolding prophecy. 
John Fahy

\section{References}

Babb, L. (1982) 'Amnesia and Remembrance in a Hindu Theory of History'. Asian Folklore Studies. Vol. 41 (1): 49-66.

Connerton, P. (1989) How Societies Remember. Cambridge: Cambridge University Press.

Hartley, L.P. (1958) The Go-Between. London: Penguin.

Moore, H. (2011) Still Life: Hopes, Desires and Satisfactions. Cambridge: Polity Press.

Munn, N. (1992) 'The Cultural Anthropology of Time: A Critical Essay'. Annual Review of Anthropology. Vol. 2: 93-1.

Prabhupada, A.C.B.S. (1975) Sri Caitanya-caritamrita. Los Angeles: The Bhaktivedanta Book Trust. Sarbadhikary, S. (2013) ‘Discovering Gupta-Vrindavan: Finding Selves and Places in the Storied Landscape'. Contributions to Indian Sociology. Vol. 47 (1): 113-140.

Sardella, F. (2013) Modern Hindu Personalism: The History, Life, and Thought of Bhaktisiddhanta Sarasvati. Oxford: Oxford University Press.

Wallis, R. (1984) The Elementary Forms of the New Religious Life. London: Routledge \& Kegan Paul.

All photographs (C) John Fahy 